\title{
Erratum to: Brief exposure to Pope Francis heightens moral beliefs about climate change
}

\author{
Jonathon P. Schuldt ${ }^{1}$ - Adam R. Pearson ${ }^{2}$ • \\ Rainer Romero-Canyas ${ }^{3}$ • Dylan Larson-Konar ${ }^{4}$
}

Published online: 13 February 2017

(C) Springer Science+Business Media Dordrecht 2017

Erratum to: Climatic Change

DOI: $10.1007 / \mathrm{s} 10584-016-1893-9$

Missing from Fig. 1 is the text of the stimulus question that was used to assess awareness of Pope Francis's views on climate change, which was displayed directly beneath the image of the pope and read: "Last year, Pope Francis and the Catholic Church issued an Encyclical Letter that called for people of all faiths to work together to address climate change and to better protect the environment. How much have you heard or read about this? \{Nothing at all; A slight amount; A moderate amount; A large amount; An extreme amount\}"

The online version of the original article can be found at http://dx.doi.org/10.1007/s10584-016-1893-9.

Jonathon P. Schuldt

jps56@cornell.edu

1 Cornell University, Ithaca, NY, USA

2 Pomona College, Claremont, CA, USA

3 Environmental Defense Fund and Columbia University, New York, NY, USA

4 Environmental Defense Fund, New York, NY, USA 